\title{
DNA hybridisation of routinely processed tissue for detecting HPV DNA in anal squamous cell carcinomas over 40 years
}

\author{
J H Scholefield, P McIntyre, J G Palmer, P J Coates, N A Shepherd, J M A Northover
}

\begin{abstract}
To study possible changes in the incidence of human papillomavirus (HPV) associated anal squamous cell carcinomas (SCC) a simple, rapid, and sensitive technique (alkaline hydrolysis) to permit DNA hybridisation from formalin fixed, paraffin wax embedded tissue was developed. The sensitivity and specificity of the technique were established by comparison with Southern blot analysis and in situ hybridisation on the same tissue specimens. Ninety tissue specimens in a single analysis were examined using this technique. Alkaline hydrolysis was applied to fixed tissue samples which showed a two-fold increase over the past 10 years in the percentage of anal cancers containing HPV type 16 DNA when compared with the previous 30 years using 207 cases of anal cancer collected over a 40 year period.

This method has several advantages over the polymerase chain reaction as it is simple, relatively inexpensive, and may be widely applied to the detection and quantification of DNA sequences, including cellular oncogenes.
\end{abstract}

Though the association between squamous cell carcinoma of the uterine cervix and HPV type 16 has been well documented, the association between anal squamous cell carcinoma and the same HPV type has only recently been described. ${ }^{1}$ To determine whether human papillomavirus (HPV)-associated anal squamous cell carcinoma (SCC) is a relatively new entity or has existed for many years a group of tumour specimens dating back to 1948 were examined for the presence of HPV type 16 DNA. During the course of this investigation we identified the need for a simple, rapid, and sensitive method for the detection of HPV DNA in large numbers of formalin fixed, paraffin wax embedded tissue specimens. Although DNA has been successfully extracted from formalin fixed tissue specimens, ${ }^{2}$ the method requires the destruction of large amounts of material, and the outcome of subsequent Southern blot analysis has been inconsistent. Currently, the only satisfactory techniques for the examination of formalin fixed, paraffin wax embedded tissue are in situ hybridisation and the polymerase chain reaction, though the latter is not widely available at present. In situ hybridisation has been used to show HPV DNA in anal cancer tissue ${ }^{3}$ but is generally considered to be less sensitive than Southern blot analysis performed on fresh tissue, and in our experience has proved technically demanding and time consuming, particularly when applied to large numbers of specimens. A new sensitive method was therefore sought which would allow many specimens of formalin fixed and paraffin wax embedded tissue to be screened simultaneously for HPV DNA sequences without the destruction of large amounts of tissue.

\section{Methods}

\section{ALKALINE HYDROLYSIS}

McIntyre and Stark recently described a method of DNA hybridisation which had been developed for the detection and quantitation of specific DNA sequences in small numbers of tissue culture cells. ${ }^{4}$ This method uses alkali to hydrolyse tissue proteins while denaturing but preserving DNA. Alkaline hydrolysis liberates fragments of DNA which are then dotted on to a nylon membrane for hybridisation. This study was performed using a modification of this method to examine formalin fixed and paraffin wax embedded tissue.

In the experiments performed by McIntyre and Stark $^{4}$ the optimal number of cells to detect a single copy gene with minimal background was 10000 . We calculated that a single $5 \mu \mathrm{m}$ section from an anal squamous cell carcinoma of $1 \mathrm{~cm}^{2}$ in area contained about a million cells; based on this calculation a single $5 \mu \mathrm{m}$ histological section was used for all our methodological experiments.

A $5 \mu \mathrm{m}$ section of formalin fixed, paraffin wax embedded tissue was cut using a microtome and placed in a microcentrifuge tube. The tissue was dewaxed in $1 \mathrm{ml}$ of xylene, and the xylene removed by rinsing three times in $1 \mathrm{ml}$ of $98 \% \mathrm{v} / \mathrm{v}$ ethanol using pulsed spins in a microcentrifuge to pellet the tissue at each step. After air drying the tissue was stored frozen at $-20^{\circ} \mathrm{C}$ until needed.

The hydrolysis was performed in $250 \mu \mathrm{l}$ of $0.4 \mathrm{M}$ sodium hydroxide at $80^{\circ} \mathrm{C}$ for one hour; the resulting suspension was cooled to room temperature and $100 \mu \mathrm{l}$ of supernate was pipetted on to a nylon membrane (Gene Screen Plus, New England Nuclear, Boston, Massachussets) through a dot blot (BioRad, Amersham) apparatus. Each of the wells was rinsed with $100 \mu \mathrm{l}$ of $0.4 \mathrm{M} \mathrm{NaOH}$, the manifold was taken apart, and the membrane was washed with $2 \times$ SSC before being pre-hybridised and subsequently probed with an HPV 16 DNA probe labelled with ${ }^{32} \mathrm{P}$ dCTP by random 


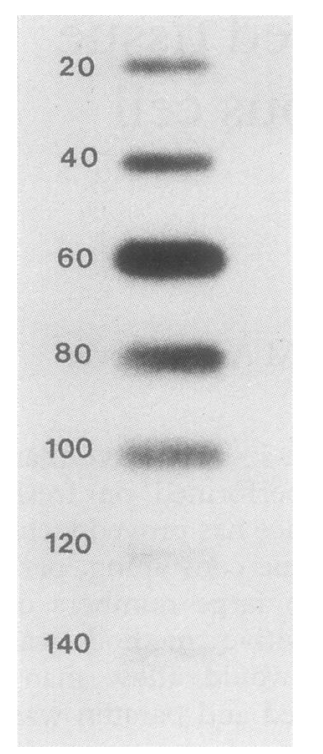

Figure 1

Autoradiograph of time course for alkaline hydrolysis of a $5 \mu \mathrm{m}$ section from a colonic DNA probe, which shows that the maximum amount of DNA was available for hybridisation at 60 minutes. Hybridisation and washing were performed under stringent conditions. tumour using a HeLa total

priming. ${ }^{5}$ Washing was performed in $0.1 \times \mathrm{SSC}$ at $65^{\circ} \mathrm{C}$. Autoradiography was performed at $-70^{\circ} \mathrm{C}$ using Kodak XAR5 film between two intensifying screens.

A preliminary series of experiments was performed to establish the optimal conditions for hydrolysis for formalin fixed, paraffin wax embedded tissue using $5 \mu \mathrm{m}$ sections cut from a single block of a colonic tumour. Alkaline hydrolysis was carried out at $80^{\circ} \mathrm{C}^{4}$ for varying periods (fig 1) and in different concentrations of sodium hydroxide. Using a radiolabelled human cellular DNA probe (HeLa), it was established that the amount of DNA liberated from the hydrolysis reaction was consistent (fig 2) and that the optimal conditions for hydrolysis were 60 minutes at $80^{\circ} \mathrm{C}$ in $0.4 \mathrm{M}$ sodium hydroxide.

Having established the optimal conditions for hydrolysis, the sensitivity of the method was investigated by its ability to detect a single copy gene (2-5 A synthetase) ${ }^{6}$ from a single tissue section.

The practical application of the technique was tested by examining 50 anal squamous cell carcinomas for HPV 16 DNA sequences. These tumours had already been examined by Southern blot analysis of fresh tissue and by in situ hybridisation of formalin fixed tissue. All the anal cancers in this series were squamous cell carcinomas.

\section{SOUTHERN BLOTTING}

DNA was extracted from fresh anal cancer tissue using proteinase $\mathrm{K}$ digestion followed by phenol chloroform extraction. ${ }^{7}$ DNA $(10 \mu \mathrm{g})$ was digested with restriction enzymes $\mathrm{Bam} \mathrm{H1}$, Pst 1 , and Hind III, underwent electrophoresis performed in a $1 \%$ agarose gel, and was transferred to a nylon membrane using the alkaline transfer technique. ${ }^{8}$

All hybridisations were performed under "stringent conditions" $(0.9 \mathrm{M} \mathrm{NaCl}$ and $50 \%$ formamide at $42^{\circ} \mathrm{C}$ ) with a radiolabelled HPV 16 DNA probe. The filters were washed under stringent conditions $\left(0.1 \times \mathrm{SSC}\right.$ at $\left.65^{\circ} \mathrm{C}\right)$. Autoradiography at $-70^{\circ} \mathrm{C}$ was carried out as above.

IN SITU HYBRIDISATION

Formalin fixed, paraffin wax embedded tissue

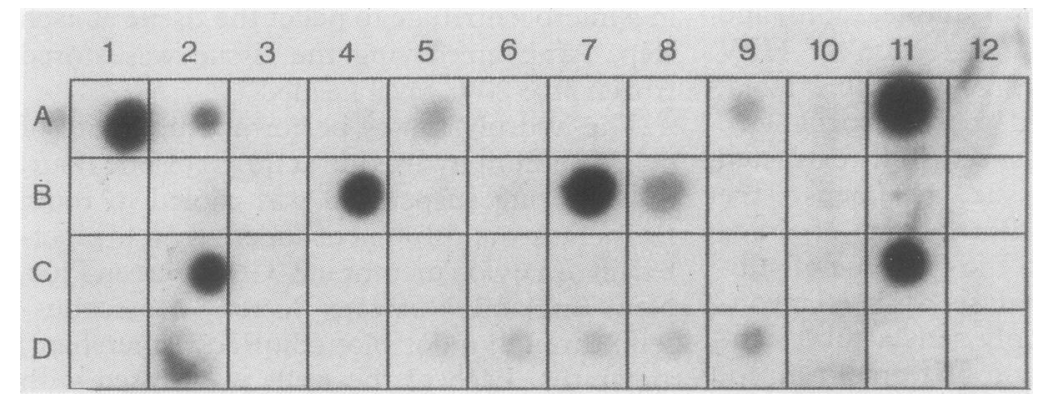

Figure 2 Autoradiograph of alkaline hydrolysis using a single $5 \mu \mathrm{m}$ section from 36 anal cancers (rows $A-C 1-12$ ): row $D$ contains negative and positive controls, purified HPV $11 \mathrm{DNA}$ in wells 1-4 (40-70 pg), purified HPV $16 \mathrm{DNA}$ in wells 5-7 (30$H P V$
$70 \mathrm{pg}), 0.2 \mu \mathrm{g} C \mathrm{CaSki} D N A$ in wells 8 and 9 , and purified $\mathrm{HPV}$. $6 \mathrm{DNA}$ in wells $10-12$ $(50-70 \mathrm{pg})$. The signal in D2 is artefactual. The filter was hybridised with HPV type $16 D N A$ and exposed to Kodak XAR 5 film for 48 hours. sections were dewaxed in xylene, rinsed in ethanol, and endogenous peroxidase activity was blocked by treatment with $0.35 \%$ hydrogen peroxide in methanol. Sections were digested with protease (type 24 ) for 15 minutes, rinsed in phosphate buffered saline, and dehydrated through alcohol. Hybridisation was carried out using a biotinylated HPV 16 DNA probe in hybridisation medium containing $50 \%$ formamide for eight hours. Washing was performed at $42^{\circ} \mathrm{C}$ in $0.1 \times$ SSC. The biotinylated HPV 16 DNA was detected using a peroxidase streptavidin biotin complex and the oxidation of diaminobenzidine to produce a brown precipitate. The sections were counterstained with haematoxylin. Details of the method used have been published by Coates et al. ${ }^{9}$

To show how alkaline hydrolysis can be applied to fixed tissue we used this technique to examine 207 anal squamous cell carcinomas which had been collected over 40 years at one hospital. The method was applied as described above. The positive and negative controls used were tumours which had been shown to be positive and negative for HPV type $16 \mathrm{DNA}$ by Southern blot which is the accepted "gold standard" technique.

A linearised HPV 16 DNA insert cloned in the plasmid SP 64 at the Bam H1 site was prepared, using a previously described method. ${ }^{7}$ The probes for Southern blotting and alkaline hydrolysis were radiolabelled to a specific activity of $10^{6}$ counts $/ \mathrm{ml}$ by random priming, according to the method of Feinberg and Vogelstein. ${ }^{5}$ Biotinylated probes for in situ hybridisation were prepared by nick translation using a commercially available kit (Gibco BRL).

CaSki DNA was used as a positive control in both the Southern blot and alkaline hydrolysis experiments. Though there was no evidence from Southern blot analysis that any of the anal squamous cell carcinomas contained HPV types $6 / 11 \mathrm{DNA}$ in addition to or instead of HPV type 16 DNA; linearised HPV types 6 and 11 were loaded as controls for type specificity, and therefore of stringency, in the alkaline hydrolysis of the formalin fixed, paraffin wax embedded anal cancer specimens.

\section{Results}

The method described permitted consistent detection of a single copy gene (2-5 A synthetase) in the DNA liberated from one $5 \mu \mathrm{m}$ section of fixed tissue, $1 \mathrm{~cm}^{2}$ in size, which is estimated to contain about $10^{6}$ cells. The HeLa total DNA probe was used to show that roughly the same amount of hybridisable DNA was liberated in each tissue section (fig 1).

Twenty five of 50 anal squamous cell carcinomas were found to contain HPV DNA type 16 by Southern blot analyis. The alkaline hydrolysis method showed that 24 of the same 25 tumours shown by Southern blot analysis to contain HPV type 16 DNA were also positive (fig 2). In contrast, only 18 of the same tumours were positive for HPV type 16 DNA by in situ hybridisation. All the tumours negative by Southern blot analysis were also negative by in 
Table 1 Comparison of results of alkaline hydrolysis with Southern blot and in situ hybridisation

\begin{tabular}{lll}
\hline & \multicolumn{2}{l}{ Tumours $(n=50)$} \\
\cline { 2 - 3 } & HPV positive & HPV negative \\
\hline Alkaline hydrolysis & 24 & 26 \\
Southern blot & 25 & 25 \\
In situ hybridisation & 18 & 32 \\
\hline
\end{tabular}

situ hybridisation and by the alkaline hydrolysis method (table 1). The seven tumours negative by in situ hybridisation but positive by Southern blot analysis were all tumours which seemed to contain low copy numbers of HPV type 16 DNA on the autoradiograph (probably less than 10 copies per cell). Though estimation of copy number from an autoradiograph is subjective and is only approximate, the sensitivity of in situ hybridisation in our hands seemed to be similar to that achieved by others using this technique. $^{10}$

There were no false positive results by either in situ hybridisation or alkaline hydrolysis. Seven cases were HPV 16 DNA negative by in situ hybridisation but positive by Southern blot analysis. These tumours contained less than 10 copies a cell. An estimate of copy number of the HPV type 16 genome was taken from the autoradiograph of the Southern blot. The single anal squamous cell carcinoma which contained HPV type 16 DNA by Southern blot analysis but was negative by alkaline hydrolysis contained a low copy number of HPV type 16 DNA on the Southern blot. Human papillomavirus type 18 was found in one tumour by Southern blot analysis; this tumour did not contain any HPV 16 DNA and was negative for HPV type 16 DNA by alkaline hydrolysis.

These results suggest that the sensitivity of the alkaline hydrolysis method is greater than that of the in situ hybridisation technique we used. The age of the specimen did not affect the detectability of a single copy gene.

The number of cases of squamous cell carcinoma collected annually has remained relatively constant throughout this periodabout five new cases a year. Alkaline hydrolysis showed HPV type 16 DNA in 49 of 207 anal squamous cell carcinomas. The percentage of cases containing HPV type 16 DNA remained more or less constant at around $15 \%$ from 1948 to 1978 . There seems to have been a sharp increase in the percentage of HPV related anal cancers, however, over the past 10 years; during this period the percentage of anal cancers associated with HPV type 16 increased to $50 \%$ (table 2) (global $\chi^{2}=15.58 \mathrm{p}<0.001$ ).

Table 2 Percentage of anal squamous cell carcinomas containing HPV 16 DNA from 1948-1987

\begin{tabular}{ll}
\hline Year & $\begin{array}{l}\text { Percentage of tumours containing } \\
\text { HPV type 16 DNA }\end{array}$ \\
\hline $1948-52$ & 12 \\
$53-57$ & 14 \\
$58-62$ & 16 \\
$63-67$ & 22 \\
$68-72$ & 17 \\
$73-77$ & 19 \\
$78-82$ & 33 \\
$83-87$ & 50 \\
\hline
\end{tabular}

\section{Discussion}

We have described a simple technique for the detection of HPV DNA in fixed material which may be more sensitive than in situ hybridisation and more simple than Southern blotting while maintaining a similar sensitivity. This method is considerably less time consuming than either in situ hybridisation or Southern blotting and has been applied to 90 samples in a single analysis. A further major advantage of this technique compared with the methods of DNA extraction from fixed tissue is that alkaline hydrolysis is very economical in its use of tissue, using only a single section an experiment and thereby allowing other techniques such as in situ hybridisation to be performed on adjacent tissue sections.

Alkaline hydrolysis is capable of detecting HPV type 16 DNA from a single section cut from a standard histological block. The specificity of the technique is shown by the fact that there were no false positive results. The signal seen in well D2 of fig 2 is thought to be artefactual as it is irregular in shape and all the other controls in the adjacent wells are satisfactory.

Human papillomavirus associated anal squamous cell carcinoma is not a new disease, but this study suggests that its incidence seems to be increasing. Though this study of old anal cancer specimens has been performed on histological specimens from one centre with a special interest in the disease, this series of cases probably represents the largest collection of tissue from anal cancers available in this country. It is difficult to extrapolate the data presented here to identify national trends, particularly as national data collected by the Office of Population Censuses and Surveys $(\mathrm{OPCS})^{11}$ have only collected data on anal and rectal tumours as separate entities since 1984 .

The trend shown in this study suggests an increase in the percentage of anal cancers containing HPV type 16 DNA over the past 10 years compared with the percentage in the previous 30 years (table 2) (global $\chi^{2}, 1 \mathrm{df}$ $15.58, \mathrm{p}<0.001)$. This may reflect the sharp increase in HPV infection reported in genitourinary clinics over the same period. ${ }^{12}$ The data available on the national incidence of anal cancers during this time period is limited as anal cancer registrations have only been separated from rectal cancer registrations by the International Classification of Diseases since 1980 (ICD 9). As a result of this, the clinical importance of finding an increasing prevalence of HPV associated anal cancer in one centre is difficult to interpret and further studies using anal cancer material from several centres may be helpful.

In the future, polymerase chain reaction may offer an even more sensitive method for examinations of fixed tissues for specific DNA sequences, ${ }^{13}$ but the technique described in the present study is simple, rapid, quantitative and does not demand great technical expertise.

In a much smaller study of old cervical cancer tissues, in which HPV type 16 DNA was identified by in situ hybridisation, HPV type 16 DNA was identified in a sample dating back 
to $1932 .{ }^{14}$ It is difficult to obtain useful data on a possible change in the incidence of HPV related cervical cancer tissues from this study as only 30 cases of invasive cervical cancer were studied.

As a simple, sensitive, and inexpensive technique for the examination of formalin fixed, and paraffin wax embedded tissue specimens, alkaline hydrolysis has many potential applications on oncogene research. Quantitation of gene copy number, as described by McIntyre and Stark, using a scanning densitometer may provide a further valuable application of this technique-for example, in screening colorectal, cervical, and bronchial carcinomas for $c$ $m y c$ amplification. The polymerase chain reaction cannot permit such quantification, is not widely available, and is relatively expensive.

We are grateful to Dr L V Crawford of the ICRF Molecular Virology Laboratory and Dr G Stark of the ICRF Molecular Biology Laboratory who kindly advised us during the course of this work and helped in the preparation of this manuscript. We are also grateful to Mrs Anne Murray for technical assistance and to Ms S B Love for statistical advice.

1 Palmer JG, Shepherd NA, Jass JR, et al. Human papillomavirus type $16 \mathrm{DNA}$ in anal squamous cell carcinoma. Lancet 1987;ii:42.

2 Mark A, Trowell H, Dyall Smith ML, et al. Extraction of DNA from formalin fixed paraffin embedded pathology specimens and its use in hybridisation (histo blot) assays. Application to the detection of human papillomavirus Wells. Nucleic Acid Res 1987;15:8565.

ells M, Griffiths S, Lewis F, Bird C. Demonstration of human papillomavirus types in paraffin processed tissue from human anogenital lesions by in situ DNA hybridisation. J Pathol 1987;152:77-82.

4 McIntyre P, Stark G. A quantitative method for analysing specific DNA sequences from whole cells. Anal Biochem 1988;174:209-14

5 Feinberg AP, Vogelstein B. A technique for radiolabelling DNA restriction endonuclease fragments to high specific activity. Analyt Biochem 1983;132:6-13.

6 Saunders M, Gewart DR, Tugwell ME, et al. Human 2-5A synthetase: Characterisation of a novel cDNA and corresponding gene structure. $E M B O J 1985 ; 4: 1761-8$.

7 Manniatis T, Fritsch EF, Sambrook J. Molecular Cloning, a Laboratory Manual. New York: Cold Spring Harbor Laboratory Manual.

8 Reed KC, Mann DA. Rapid transfer of DNA from agarose gels to nylon membranes. Nucleic Acids Res 1985;13: 7207-21.

9 Coates PJ, Hall PA, Butler MG, et al. Rapid technique of DNA-DNA in situ hybridisation on formalin fixed tissue sections using microwave irradiation. J Clin Pathol 1987;40:865-9.

10 Burns J, Graham AK, Fraik G, et al. Detection of low copy number human papillomavirus DNA and RNA in routine paraffin sections of cervix by non isotopic in situ hybridisation. J Clin Pathol 1987;40:858-64.

11 Office of Population Censuses and Surveys. Cancer Statistics Registrations. London: HMSO, 1984.

12 Sexually transmitted disease surveillance in Britain 1984. Communicable Disease Surveillance Centre. Br Med 1986;296:942-3.

13 Young LS, Bevan IS, Johnson MA, et al. The polymerase chain reaction: a new epidemiological tool for investigat ing cervical human papillomavirus infection. $\mathrm{Br} M e d$ 1989;298:14-18.

14 Collins JE, Jenkins D, McCance DJ. Detection of human papillomavirus DNA sequences by in situ hybridisation in cervical intraepithelial neoplasia and invasive carcinoma: a retrospective study. J Clin Pathol 1988;41:289-95. 